\title{
Vibration Analysis of Steel-Concrete Composite Box Beams considering Shear Lag and Slip
}

\author{
Zhou Wangbao, ${ }^{1}$ Li Shu-jin, ${ }^{1}$ Jiang Lizhong, ${ }^{2}$ and Qin Shiqiang ${ }^{1}$ \\ ${ }^{1}$ School of Civil Engineering and Architecture, Wuhan University of Technology, Wuhan 430070, China \\ ${ }^{2}$ School of Civil Engineering, Central South University, Changsha 410075, China \\ Correspondence should be addressed to Zhou Wangbao; zhwb@whut.edu.cn
}

Received 21 January 2015; Revised 15 March 2015; Accepted 15 March 2015

Academic Editor: Giovanni Garcea

Copyright (c) 2015 Zhou Wangbao et al. This is an open access article distributed under the Creative Commons Attribution License, which permits unrestricted use, distribution, and reproduction in any medium, provided the original work is properly cited.

\begin{abstract}
In order to investigate dynamic characteristics of steel-concrete composite box beams, a longitudinal warping function of beam section considering self-balancing of axial forces is established. On the basis of Hamilton principle, governing differential equations of vibration and displacement boundary conditions are deduced by taking into account coupled influencing of shear lag, interface slip, and shear deformation. The proposed method shows an improvement over previous calculations. The central difference method is applied to solve the differential equations to obtain dynamic responses of composite beams subjected to arbitrarily distributed loads. The results from the proposed method are found to be in good agreement with those from ANSYS through numerical studies. Its validity is thus verified and meaningful conclusions for engineering design can be drawn as follows. There are obvious shear lag effects in the top concrete slab and bottom plate of steel beams under dynamic excitation. This shear lag increases with the increasing degree of shear connections. However, it has little impact on the period and deflection amplitude of vibration of composite box beams. The amplitude of deflection and strains in concrete slab reduce as the degree of shear connections increases. Nevertheless, the influence of shear connections on the period of vibration is not distinct.
\end{abstract}

\section{Introduction}

The advantages of fully making use of compressive strength of concrete and tensile strength of steel make composite box beams popular in the bridge engineering. For composite box beams with large flange width, however, there are shear lag effects in the top concrete slab and bottom plates of steel box beams due to the nonuniform transverse distribution of shear stress across section. In addition, due to the fact that the shear connectors between the steel beam and concrete slab cannot be absolutely rigid, there exists relative slip between them even for fully shear connected beams. Therefore, the behavior of steel-concrete composite box beams suffers from coupled effects of both the shear lag and shear slip [1-5]. Gara [6, 7] presented a beam finite element, in which the warping of the slab cross section was considered, for the long-term analysis of steel-concrete composite decks taking into account the shear lag in the slab and the partial shear interaction at the slab-beam interface. By using energy variation method,
Zhou et al. [5] derived the governing differential equations and boundary conditions of the steel-concrete composite box beams by considering the longitudinal warp caused by shear lag effects and slip between steel beams and concrete slabs.

Morassi and Dilena [8-10] investigated an experiment on damage-induced changes in modal parameters of steelconcrete composite beams subject to small vibrations, and the experiments revealed that flexural frequencies showed a rather high sensitivity to damage and therefore can be considered as a valid indicator upon a diagnostic analysis. Therefore, it makes sense to study the vibration characteristic of composite beam. Adam et al. [11] analyzed the dynamic flexural behavior of elastic two-layer beams with interlayer slip by assuming the Bernoulli-Euler hypothesis to hold for each layer separately and considering a linear constitutive equation between the horizontal slip and the interlayer shear force. Biscontin et al. [12] performed an experimental analytical investigation on the dynamic behavior of I-steelconcrete composite beams subject to small vibrations, and a 
one-dimensional model of a composite beam was presented where the elements connecting the steel and reinforced concrete slab were described by means of a strain energy density function defined along the beam axis. Berczyński $[13,14]$ presented a solution of the problem of free vibrations of I-steelconcrete composite beams and found that the results obtained on the basis of the Timoshenko beam theory model achieved the highest conformity with the experimental results, both for higher and for lower modes of flexural vibrations of the beam. $\mathrm{Xu}$ and $\mathrm{Wu}$ [15] investigated the static, dynamic, and buckling behavior of partial-interaction T-composite members by taking into account the influences of rotary inertia and shear deformations and obtained the analytical expressions of the frequencies of the simply supported composite beam. Shen et al. [16] studied the dynamic behavior of partialinteraction T-composite beams by using state-space method, which was properly established via selecting the appropriate state variables, and the characteristic equations of frequency and the corresponding modal shapes of free vibration under generalized boundary conditions were then obtained. Shen and Zhong [17] examined the deformation of partially I-steelconcrete composite beams under distributed loading and free vibrations of partially I-steel-concrete composite beams under various boundary conditions, where the weak-form quadrature element method was used.

Considerable efforts have been put into the investigation of dynamic characteristics of composite beams including interface slip effects [18-22]. Most of studies focus on the Isteel beam-concrete composite beams or T-type composite beams. The studies about the dynamic characteristics of composite box beams are rare, especially the studies involving both the interface slip and shear lag in the dynamic characteristics. Based on a longitudinal warping function considering self-balancing of axial forces and the Hamilton principle, this paper deduces the governing differential equations of dynamic responses of composite box beams under arbitrarily distributed loads. It takes into account the influence of shear lag, interface slip, and shear deformation. The equations are solved by central difference methods. Numerical studies are carried out and a good agreement is achieved between results from the proposed method and finite element method using ANSYS. The influences of the shear lag effect and the degree of shear connections on the dynamic responses of composite box beams are examined and meaningful conclusions for engineering design are drawn.

\section{Basic Assumptions}

Figure 1 shows the section size and coordinate system of composite box beams. The parameters $t_{1}, t_{2}, t_{3}, t_{4}$, and $t_{4}^{*}$ are the thicknesses of the top concrete slab, cantilever plate, bottom plate, web, and top flange of steel box beam, respectively; the parameters $b_{1}, b_{2}, b_{3}, b_{4}$, and $b_{4}^{*}$ are the widths of half-top concrete slab, cantilever plate, half-bottom plate of steel beams, web of steel beams, and top flange of steel beams, respectively; the parameters $h_{c}$ and $h_{s}$ are the distances between the centroids of the concrete slab and steel beam to the slab-beam interface, respectively, and here

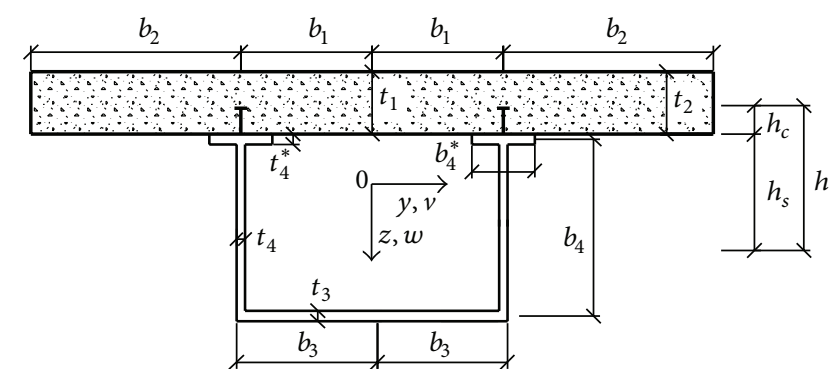

FIGURE 1: Schematic of section of steel-concrete composite box beams.

$h=h_{c}+h_{s}$. Reasonable assumptions to simplify the analysis model are made as follows.

(1) According to the displacement compatibility, the longitudinal warping function of concrete top slab, cantilever plate, bottom flange, and web of steel beams is assumed as $[5,23,24]$

$$
\begin{gathered}
g_{i}=\psi_{i}(y) U(x, t) \quad i=1,2,3,4, \\
\psi_{i}=\alpha_{i}\left(\frac{y^{2}}{b_{i}^{2}}-1\right)+\bar{d} \quad i=1,2,3,4 .
\end{gathered}
$$

Considering self-balancing of axial forces produced by longitudinal displacement yields $[5,23,24]$

$$
\begin{gathered}
\alpha_{1}=1, \quad \alpha_{2}=\frac{b_{2}^{2}}{b_{1}^{2}}, \\
\alpha_{3}=z_{b} \frac{b_{3}^{2}}{\left(b_{1}^{2} z_{t}\right)}, \quad \alpha_{4}=0 .
\end{gathered}
$$

Considering self-balancing of axial forces produced by longitudinal warping function yields $[5,23,24]$

$$
\int_{A} \psi d A=0
$$

Substituting (2) into (4) obtains the constant term of longitudinal warping displacements as follows:

$$
\bar{d}=\frac{2\left(\alpha_{1} A_{1} / n+\alpha_{2} A_{2} / n+\alpha_{3} A_{3}\right)}{\left(3 A_{0}\right)} .
$$

For $i=2$, replace $y$ with $\bar{y}=b_{1}+b_{2}-y \cdot z_{t}$ and $z_{b}$ are the $z$-coordinates of centroids of the concrete slab and bottom flange; $z_{0}$ is the $z$-coordinate of the slab-beam interface; $\bar{d}$ is the constant term of longitudinal warping displacements; $U(x, t)$ is the function of the amplitude of warping displacements; $\psi_{i}$ is the warping shape function of the beam section, as shown in Figure $2 ; \alpha_{i}$ is the self-balancing coefficient of section warping; $n=E_{s} / E_{c}$, and $E_{s}$ and $E_{c}$ are the modulus of elasticity of steel and concrete, respectively;

$$
\begin{gathered}
A_{1}=2 b_{1} t_{1}, \quad A_{2}=2 b_{2} t_{2}, \\
A_{3}=2 b_{3} t_{3}, \quad A_{4}=2\left(b_{4} t_{4}+b_{4}^{*} t_{4}^{*}\right), \\
A_{0}=\frac{\left(A_{1}+A_{2}\right)}{n}+A_{3}+A_{4} .
\end{gathered}
$$




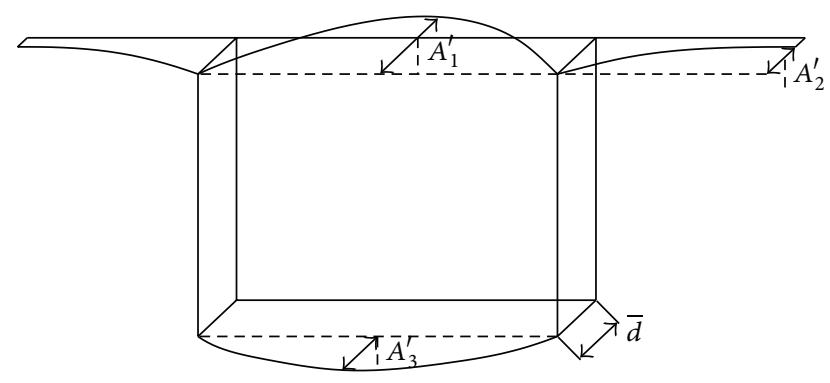

FIgURE 2: Schematic of warping shape function.

(2) The longitudinal displacement of any point in the transverse section of composite box beams is assumed as the superposition of the longitudinal displacement based on the plain section assumption, the longitudinal warping displacement due to the shear lag, and longitudinal displacement due to the relative interface slip. It can be expressed as $[5,23,24]$

$$
\begin{gathered}
u_{i}=k_{c} \xi-\left(z-z_{t}\right) \theta+g_{i} \quad i=1,2, \\
u_{i}=k_{s} \xi-\left(z-z_{s}\right) \theta+g_{i} \quad i=3,4, \\
k_{c}=-\frac{A_{s}}{A_{0}}, \quad k_{s}=\frac{A_{c}}{\left(n A_{0}\right)}, \\
\zeta(x, t)=\xi+h \theta,
\end{gathered}
$$

where $\theta(x, t)$ is the rotation of the beam section, $A_{w}=2 b_{4} t_{4}$, $A_{s}=A_{3}+A_{4}$ is the cross section area of steel beams, $A_{c}=$ $A_{1}+A_{2}$ is the cross section area of concrete slabs, $\xi(x, t)$ is the longitudinal displacement difference between centroids of the concrete slab and steel beam, $\zeta(x, t)$ is slab-beam interface slip, $z_{s}$ is the $z$-coordinate of the centroid of the steel beam, $k_{s}$ is the ratio between steel beam's longitudinal displacement due to the relative interface slip and relative interface slip, and $k_{c}$ is the ratio between concrete slab's longitudinal displacement due to the relative interface slip and relative interface slip.

(3) The vertical compression and transverse strain of concrete slabs and steel beams are ignored $[5,23]$.

\section{Vibration Differential Equation and Boundary Conditions}

3.1. The Strain of the Cross Section. The sectional strain can be obtained from the above longitudinal displacement of composite beam sections as

$$
\begin{gathered}
\varepsilon_{x i}=k_{c} \frac{\partial \xi}{\partial x}-\left(z-z_{t}\right) \frac{\partial \theta}{\partial x}+\psi_{i} \frac{\partial U}{\partial x} \quad i=1,2, \\
\varepsilon_{x i}=k_{s} \frac{\partial \xi}{\partial x}-\left(z-z_{s}\right) \frac{\partial \theta}{\partial x}+\psi_{i} \frac{\partial U}{\partial x} \quad i=3,4, \\
\gamma_{x y i}=\frac{\partial u_{i}}{\partial y}=\frac{\partial \psi_{i}}{\partial y} U \quad i=1,2,3, \\
\gamma_{x z}=\frac{\partial w}{\partial x}-\theta,
\end{gathered}
$$

where $\varepsilon_{i}(i=1,2,3,4)$ are the longitudinal strain of the top concrete slab, cantilever plate, bottom flange, and web of steel beams, respectively; $\gamma_{i}(i=1,2,3)$ are the shear strain of top concrete slab, cantilever plate, and bottom plate of steel beams, respectively; $\gamma_{x z}$ is the shear strain of the web of steel beams; $w(x, t)$ is the vertical deflection of composite box beams.

3.2. Total Potential Energy of the Composite Box Beam. The strain energy of composite box beams is defined as [5]

$$
\begin{aligned}
V= & 0.5 \int_{0}^{L} \int_{A_{0}}\left(E_{s} \varepsilon^{2}+G_{s} \gamma^{2}\right) d A d x \\
& +0.5 \int_{0}^{L} k_{\mathrm{sl}} \zeta^{2} d x+\frac{0.5 G_{s} A_{0}\left(w^{\prime}-\theta\right)^{2}}{\alpha_{s}} .
\end{aligned}
$$

Substituting (10)-(11) into (12) gives the strain energy of composite box beams as

$$
\begin{array}{r}
V=0.5 \int_{0}^{L}\left[D \xi^{\prime 2}+F U^{\prime 2}+2 H U^{\prime} \xi^{\prime}+I \theta^{\prime 2}+J U^{2}\right. \\
\left.\quad-2 S U^{\prime} \theta^{\prime}+k_{\mathrm{sl}} \zeta^{2}+\frac{G_{s} A_{0}\left(w^{\prime}-\theta\right)^{2}}{\alpha_{s}}\right] d x,
\end{array}
$$

where $D=E_{c} k_{c}^{2} A_{c}+E_{s} k_{s}^{2} A_{s}, F=E_{c} B_{c f}+E_{s} B_{s f}, H=E_{c} B_{c h}+$ $E_{s} B_{s h}, I=E_{c} B_{c i}+E_{s} B_{s i}, J=G_{c} B_{c j}+G_{s} B_{s j}, S=E_{c} B_{c s}+E_{s} B_{s s}$, $B_{c f}=\int_{A_{c}} \psi^{2} d A, B_{s f}=\int_{A_{s}} \psi^{2} d A, B_{c h}=\int_{A_{c}} k_{c} \psi d A, B_{s h}=$ $\int_{A_{s}} k_{s} \psi d A, B_{c i}=\int_{A_{c}}\left(z-z_{t}\right)^{2} d A, B_{s i}=\int_{A_{s}}\left(z-z_{s}\right)^{2} d A, B_{c j}=$ $\int_{A_{c}}(\partial \psi / \partial y)^{2} d A, B_{s j}=\int_{A_{3}}(\partial \psi / \partial y)^{2} d A, B_{c s}=\int_{A_{c}}\left(z-z_{t}\right) \psi d A$, $B_{s s}=\int_{A_{s}}\left(z-z_{s}\right) \psi d A$, and $\alpha_{s}$ is the correction coefficient of shear deformation. Considering that the webs bear most of the vertical shear force in section, here the value of $\alpha_{s}$ is taken as $A_{0} /\left(2 b_{4} t_{4}\right)$, and $2 b_{4} t_{4}$ is the section area of webs; $k_{\mathrm{sl}}$ is the slip stiffness between the concrete slab and the steel beam; $L$ is the span of the composite box beam; $G_{s}$ is the shear modulus of the steel beam.

The kinetic energy of the composite box beam is [5]

$$
T=\frac{1}{2} \int_{0}^{L} \int_{A}\left(\rho \dot{u}^{2}+m \dot{w}^{2}\right) d A d x .
$$

Substituting of (7) and (8) yields

$T$

$$
=\frac{1}{2} \int_{L}\left(m \dot{w}^{2}+D_{1} \dot{\xi}^{2}+F_{1} \dot{U}^{2}+2 H_{1} \dot{U} \dot{\xi}+I_{1} \dot{\theta}^{2}-2 S_{1} \dot{U} \dot{\theta}\right) d x,
$$

where $D_{1}=\rho_{c} k_{c}^{2} A_{c}+\rho_{s} k_{s}^{2} A_{s}, F_{1}=\rho_{c} B_{c f}+\rho_{s} B_{s f}, H_{1}=\rho_{c} B_{c h}+$ $\rho_{s} B_{s h}, I_{1}=\rho_{c} B_{c i}+\rho_{s} B_{s i}, S_{1}=\rho_{c} B_{c s}+\rho_{s} B_{s s}, m=\rho_{c} A_{c}+\rho_{s} A_{s}$, $A=A_{s}+A_{c}$, and $\rho_{c}$ and $\rho_{s}$ are the density of concrete slabs and steel beams, respectively. 
The work done by the external loads can be expressed as

$$
W=\int_{L} q(x, t) w d x,
$$

where $q(x, t)$ is the distribution function of arbitrary load.

3.3. Vibration Differential Equation and Boundary Conditions The governing equations of vibration of composite box beams and corresponding boundary conditions can be deduced based on Hamilton principle as

$$
\begin{aligned}
& F U^{\prime \prime}+H \xi^{\prime \prime}-J U-S \theta^{\prime \prime}-F_{1} \ddot{U}-H_{1} \ddot{\xi}+S_{1} \ddot{\theta}=0, \\
& H U^{\prime \prime}+D \xi^{\prime \prime}-k_{\mathrm{sl}} \zeta-H_{1} \ddot{U}-D_{1} \ddot{\xi}=0, \\
& \frac{G_{s} A_{0}\left(w^{\prime \prime}-\theta^{\prime}\right)}{\alpha_{s}}-m \ddot{w}+q(x, t)=0, \\
& \frac{G_{s} A_{0}\left(w^{\prime}-\theta\right)}{\alpha_{s}}+I \theta^{\prime \prime}-S U^{\prime \prime}-k_{\mathrm{sl}} \zeta h+S_{1} \ddot{U}-I_{1} \ddot{\theta}=0, \\
& \left.\left(F U^{\prime}+H \xi^{\prime}-S \theta^{\prime}\right) \delta U\right|_{0} ^{L}=0, \\
& \left.\left(D \xi^{\prime}+H U^{\prime}\right) \delta \xi\right|_{0} ^{L}=0 \\
& \left.\frac{G_{s} A_{0}\left(w^{\prime}-\theta\right)}{\alpha_{s}} \delta w\right|_{0} ^{L}=0 \\
& \left.\left(I \theta^{\prime}-S U^{\prime}\right) \delta \theta\right|_{0} ^{L}=0 .
\end{aligned}
$$

Taking a simply supported beam as example, (21)-(24) give boundary conditions as

$$
\begin{gathered}
U^{\prime}(L, t)=\xi^{\prime}(L, t)=\theta^{\prime}(L, t)=w(L, t)=0, \\
U^{\prime}(0, t)=\xi^{\prime}(0, t)=\theta^{\prime}(0, t)=w(0, t)=0
\end{gathered}
$$

given the initial conditions as

$$
\begin{aligned}
U(x, 0)=U_{0}(x), & \dot{U}(x, 0)=\bar{U}_{0}(x), \\
\xi(x, 0)=\xi_{0}(x), & \dot{\xi}(x, 0)=\bar{\xi}_{0}(x), \\
w(x, 0)=w_{0}(x), & \dot{w}(x, 0)=\bar{w}_{0}(x), \\
\theta(x, 0)=\theta_{0}(x), & \dot{\theta}(x, 0)=\bar{\theta}_{0}(x) .
\end{aligned}
$$

\section{Finite Difference Method of Vibration Differential Equation}

4.1. Difference Scheme. Let solution domain be $\sigma=\{(x, t) \mid$ $0 \leq x \leq L, 0 \leq t \leq T\} ; T$ is the end time of solution; a rectangular mesh is made in the solution area with a time step of $\tau$ and space step of $v$, so that

$$
\begin{aligned}
& x_{i}=i v \quad(i=0,1,2, \ldots, \bar{I}), \\
& t_{j}=j \tau \quad(j=0,1,2, \ldots, \bar{J}),
\end{aligned}
$$

where $\bar{I}=L / v, \bar{J}=T / \tau$.
Let

$$
\begin{array}{ll}
U_{i}^{j}=U\left(x_{i}, t_{j}\right), & \xi_{i}^{j}=\xi\left(x_{i}, t_{j}\right), \\
w_{i}^{j}=w\left(x_{i}, t_{j}\right), & \theta_{i}^{j}=\theta\left(x_{i}, t_{j}\right) .
\end{array}
$$

The central difference calculation of governing differential equation yields

$$
\begin{aligned}
& F \frac{U_{i+1}^{j}-2 U_{i}^{j}+U_{i-1}^{j}}{v^{2}}+H \frac{\xi_{i+1}^{j}-2 \xi_{i}^{j}+\xi_{i-1}^{j}}{v^{2}} \\
& -S \frac{\theta_{i+1}^{j}-2 \theta_{i}^{j}+\theta_{i-1}^{j}}{v^{2}}-F_{1} \frac{U_{i}^{j+1}-2 U_{i}^{j}+U_{i}^{j-1}}{\tau^{2}} \\
& -J U_{i}^{j}-H_{1} \frac{\xi_{i}^{j+1}-2 \xi_{i}^{j}+\xi_{i}^{j-1}}{\tau^{2}} \\
& +S_{1} \frac{\theta_{i}^{j+1}-2 \theta_{i}^{j}+\theta_{i}^{j-1}}{\tau^{2}}=0 \\
& (i=1, \ldots, \bar{I}-1 ; j=1,2, \ldots, \bar{J}), \\
& H \frac{U_{i+1}^{j}-2 U_{i}^{j}+U_{i-1}^{j}}{v^{2}}+D \frac{\xi_{i+1}^{j}-2 \xi_{i}^{j}+\xi_{i-1}^{j}}{v^{2}} \\
& -k_{\mathrm{sl}}\left(\xi_{i}^{j}+h \theta_{i}^{j}\right)-H_{1} \frac{U_{i}^{j+1}-2 U_{i}^{j}+U_{i}^{j-1}}{\tau^{2}} \\
& -D_{1} \frac{\xi_{i}^{j+1}-2 \xi_{i}^{j}+\xi_{i}^{j-1}}{\tau^{2}}=0 \\
& (i=1, \ldots, \bar{I}-1 ; j=1,2, \ldots, \bar{J}),
\end{aligned}
$$

$$
\begin{aligned}
& \frac{G_{s} A_{0}}{\alpha_{s}}\left(\frac{w_{i+1}^{j}-w_{i-1}^{j}}{2 v}-\theta_{i}^{j}\right)+I \frac{\theta_{i+1}^{j}-2 \theta_{i}^{j}+\theta_{i-1}^{j}}{v^{2}} \\
& -S \frac{U_{i+1}^{j}-2 U_{i}^{j}+U_{i-1}^{j}}{v^{2}}+S_{1} \frac{U_{i}^{j+1}-2 U_{i}^{j}+U_{i}^{j-1}}{\tau^{2}} \\
& \quad-I_{1} \frac{\theta_{i}^{j+1}-2 \theta_{i}^{j}+\theta_{i}^{j-1}}{\tau^{2}}-k_{\mathrm{sl}} h\left(\xi_{i}^{j}+h \theta_{i}^{j}\right)=0 \\
& \frac{G_{s} A_{0}}{\alpha_{s}}\left(\frac{w_{i+1}^{j}-2 w_{i}^{j}+w_{i-1}^{j}}{v^{2}}-\frac{\theta_{i+1}^{j}-\theta_{i-1}^{j}}{2 v}\right) \\
& +q_{i}^{j}-m \frac{w_{i}^{j+1}-2 w_{i}^{j}+w_{i}^{j-1}}{\tau^{2}}=0 \\
& (i=1, \ldots, \bar{I}-1 ; j=1,2, \ldots, \bar{J}) .
\end{aligned}
$$


The difference calculation of boundary conditions yields

$$
\begin{gathered}
\frac{U_{\bar{I}}^{j}-U_{\bar{I}-1}^{j}}{v}=\frac{U_{1}^{j}-U_{0}^{j}}{v}=0 \quad j=0,1, \ldots, \bar{J}, \\
\frac{\xi_{\bar{I}}^{j}-\xi_{\bar{I}-1}^{j}}{v}=\frac{\xi_{1}^{j}-\xi_{0}^{j}}{v}=0 \quad j=0,1, \ldots, \bar{J}, \\
w_{\bar{I}}^{j}=w_{0}^{j}=0 \quad j=0,1, \ldots, \bar{J}, \\
\frac{\theta_{\bar{I}}^{j}-\theta_{\bar{I}-1}^{j}}{v}=\frac{\theta_{1}^{j}-\theta_{0}^{j}}{v}=0 \quad j=0,1, \ldots, \bar{J} .
\end{gathered}
$$

The difference calculation of initial condition yields

$$
\begin{gathered}
U_{i}^{0}=U_{0 i}, \quad \frac{U_{i}^{1}-U_{i}^{0}}{\tau}=\bar{U}_{0 i} \quad i=0,1,2, \ldots, \bar{I}, \\
\xi_{i}^{0}=\xi_{0 i}, \quad \frac{\xi_{i}^{1}-\xi_{i}^{0}}{\tau}=\bar{\xi}_{0 i} \quad i=0,1,2, \ldots, \bar{I}, \\
w_{i}^{0}=w_{0 i}, \quad \frac{w_{i}^{1}-w_{i}^{0}}{\tau}=\bar{w}_{0 i} \quad i=0,1,2, \ldots, \bar{I}, \\
\theta_{i}^{0}=\theta_{0 i}, \quad \frac{\theta_{i}^{1}-\theta_{i}^{0}}{\tau}=\bar{\theta}_{0 i} \quad i=0,1,2, \ldots, \bar{I} .
\end{gathered}
$$

4.2. Solution Step. Let $\mathbf{U}^{j}=\left\{U_{0}^{j}, U_{1}^{j}, \ldots, U_{\bar{I}}^{j}\right\}^{T}, \xi^{j}=\left\{\xi_{0}^{j}, \xi_{1}^{j}\right.$, $\left.\ldots, \xi_{\bar{I}}^{j}\right\}^{T}, \mathbf{w}^{j}=\left\{w_{0}^{j}, w_{1}^{j}, \ldots, w_{\bar{I}}^{j}\right\}^{T}$, and $\boldsymbol{\theta}^{j}=\left\{\theta_{0}^{j}, \theta_{1}^{j}, \ldots, \theta_{\bar{I}}^{j}\right\}^{T}$. Given $\mathbf{U}^{j-1}, \boldsymbol{\xi}^{j-1}, \mathbf{w}^{j-1}, \boldsymbol{\theta}^{j-1}, \mathbf{U}^{j}, \boldsymbol{\xi}^{j}, \mathbf{w}^{j}$, and $\boldsymbol{\theta}^{j}$, the solving of $\mathbf{U}^{j+1}, \boldsymbol{\xi}^{j+1}, \mathbf{w}^{j+1}$, and $\boldsymbol{\theta}^{j+1}$ follows the steps below.

(a) Calculate $\mathbf{U}^{0}, \boldsymbol{\xi}^{0}, \mathbf{w}^{0}, \boldsymbol{\theta}^{0}, \mathbf{U}^{1}, \boldsymbol{\xi}^{1}, \mathbf{w}^{1}$, and $\boldsymbol{\theta}^{1}$ from the initial conditions given in (37).

(b) Given $\mathbf{U}^{j-1}, \boldsymbol{\xi}^{j-1}, \boldsymbol{\theta}^{j-1}, \mathbf{U}^{j}, \boldsymbol{\xi}^{j}, \mathbf{w}^{j}$, and $\boldsymbol{\theta}^{j}$, calculate $\left\{U_{1}^{j+1}, U_{2}^{j+1}, \ldots, U_{\bar{I}-1}^{j+1}\right\},\left\{\xi_{1}^{j+1}, \xi_{2}^{j+1}, \ldots, \xi_{\bar{I}-1}^{j+1}\right\}$, and $\left\{\theta_{1}^{j+1}, \theta_{2}^{j+1}, \ldots, \theta_{\bar{I}-1}^{j+1}\right\}$ from (29)-(31).

(c) Calculate $\left\{U_{0}^{j+1}, U_{\bar{I}}^{j+1}\right\},\left\{\xi_{0}^{j+1}, \xi_{\bar{I}}^{j+1}\right\}$, and $\left\{\theta_{0}^{j+1}, \theta_{\bar{I}}^{j+1}\right\}$ from (33), (34), and (36), and the solution of $\mathbf{U}^{j+1}$, $\boldsymbol{\xi}^{j+1}$, and $\boldsymbol{\theta}^{j+1}$ is obtained in combination with step (b).

(d) Given $\mathbf{w}^{j-1}, \mathbf{w}^{j}$, and $\boldsymbol{\theta}^{j}$, determine $\left\{w_{1}^{j+1}, w_{2}^{j+1}, \ldots\right.$, $\left.w_{\bar{I}-1}^{j+1}\right\}$ from (32).

(e) Calculate $\left\{w_{0}^{j+1}, w_{\bar{I}}^{j+1}\right\}$ from (35) and calculate $\mathbf{w}^{j+1}$ combined with step (d).

4.3. Degeneration of the Vibration Differential Equation. Likewise, the governing equations of vibration of composite box beams and boundary conditions without shear lag effects can be deduced as

$$
\begin{gathered}
D \xi^{\prime \prime}-k_{\mathrm{sl}} \zeta-D_{1} \ddot{\xi}=0, \\
\frac{G_{s} A_{0}\left(w^{\prime \prime}-\theta^{\prime}\right)}{\alpha_{s}}-m \ddot{w}+q(x, t)=0, \\
\frac{G_{s} A_{0}\left(w^{\prime}-\theta\right)}{\alpha_{s}}+I \theta^{\prime \prime}-k_{\mathrm{sl}} \zeta h-I_{1} \ddot{\theta}=0, \\
\left.\xi^{\prime} \delta \xi\right|_{0} ^{L}=0,\left.\quad \theta^{\prime} \delta \theta\right|_{0} ^{L}=0,\left.\quad\left(w^{\prime}-\theta\right) \delta w\right|_{0} ^{L}=0 .
\end{gathered}
$$

For beams with two ends simply supported, the boundary conditions can be expressed from (41) as

$$
\begin{aligned}
& \xi^{\prime}(L, t)=\theta^{\prime}(L, t)=w(L, t)=0, \\
& \xi^{\prime}(0, t)=\theta^{\prime}(0, t)=w(0, t)=0 .
\end{aligned}
$$

The vibration differential equation of composite box beams, without considering shear lag effects, is a degeneration of the one considering the shear lag effects, the solution method of which can be referred to in Sections 4.1 and 4.2.

\section{Analysis of Examples}

The validity of the proposed method is verified by comparing to numerical results from finite element method. The comparisons are made on four simply supported composite box beams with different degree of shear connections under suddenly imposed distributed loads. The dynamic responses of beams with and without shear lag effects are analyzed. The distributed load is taken as $q=300 \mathrm{kN} / \mathrm{m}$ with a time step of $\tau=0.00002 \mathrm{~s}$ and a space step of $v=0.3 \mathrm{~m}$. The mechanical and geometrical parameters of composite box beams are taken as $E_{s}=2.0 \times 10^{5} \mathrm{MPa}, E_{c}=4.5 \times 10^{4} \mathrm{MPa}$, $G_{s}=7.71 \times 10^{4} \mathrm{MPa}, \mu_{s}=0.28, \mu_{c}=0.18, \rho_{s}=7900 \mathrm{~kg} \cdot \mathrm{m}^{-3}$, $\rho_{c}=2400 \mathrm{~kg} \cdot \mathrm{m}^{-3}, b_{1}=b_{3}=2.5 \mathrm{~m}, b_{2}=2.0 \mathrm{~m}, b_{4}=3.0 \mathrm{~m}$, $b_{5}=0.2 \mathrm{~m}, t_{1}=t_{2}=0.3 \mathrm{~m}, t_{3}=t_{5}=0.06 \mathrm{~m}, t_{4}=0.09 \mathrm{~m}$, $L=30 \mathrm{~m}, l=0.3 \mathrm{~m}, n_{s}=2$, and $f_{s}=300 \mathrm{MPa}$.

The commercial finite element software ANSYS is used in this study. In the finite element model, the concrete slab and steel beam are modeled by SOLID65 and SHELL43 elements, respectively. Shear connector is modeled by COMBIN14 elements, being spring elements [25]. The aspect ratio of the mesh is kept close to one throughout, the mean mesh size varies from $0.2 \mathrm{~m}$ to $0.3 \mathrm{~m}$, and about 9200 finite elements in total are employed. The transverse distributed loads are imposed on the top flanges. The translational $x$ and $y$ degrees of freedom of all nodes at two ends of beams are restrained. The torsion at the beam ends is thus restrained. The translational $z$ DOF of the left end is restrained to meet the static determined requirement and allow rotation along the moment. The results are shown in Figures 3 and 4.

The $k_{\mathrm{sl}}$ is calculated as $[5,23,24]$

$$
k_{\mathrm{sl}}=\frac{K_{1}}{l} .
$$




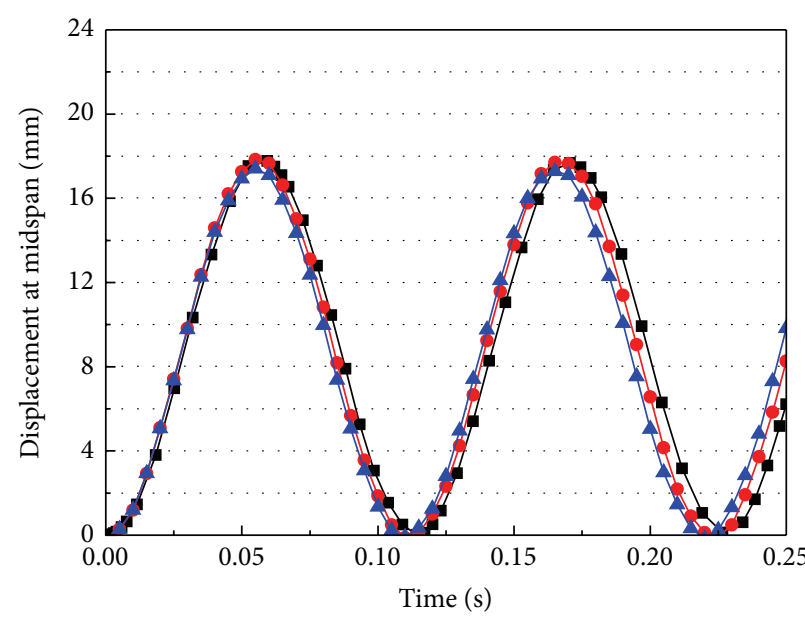

(a) $r=0.25$

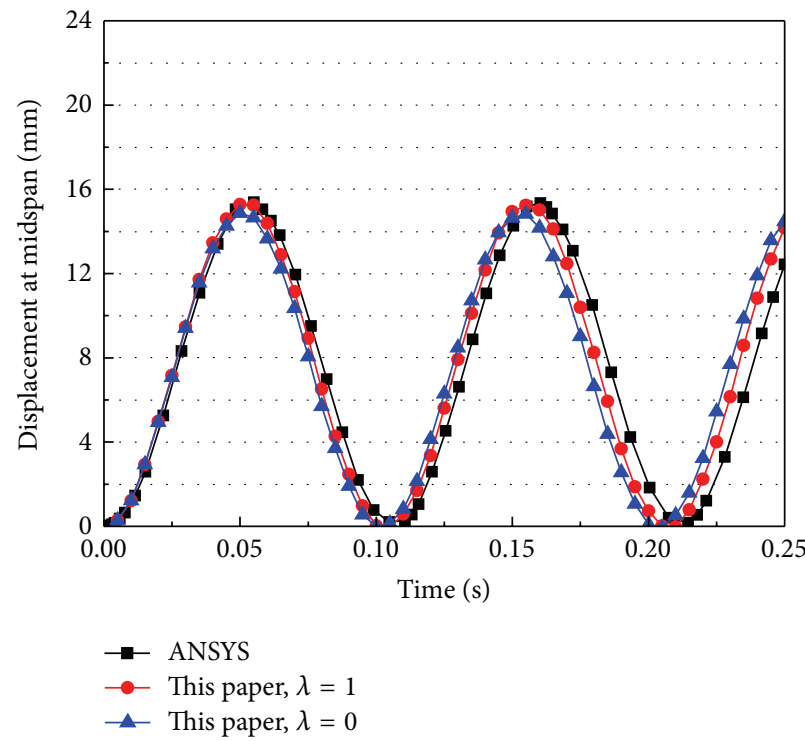

(c) $r=1.0$

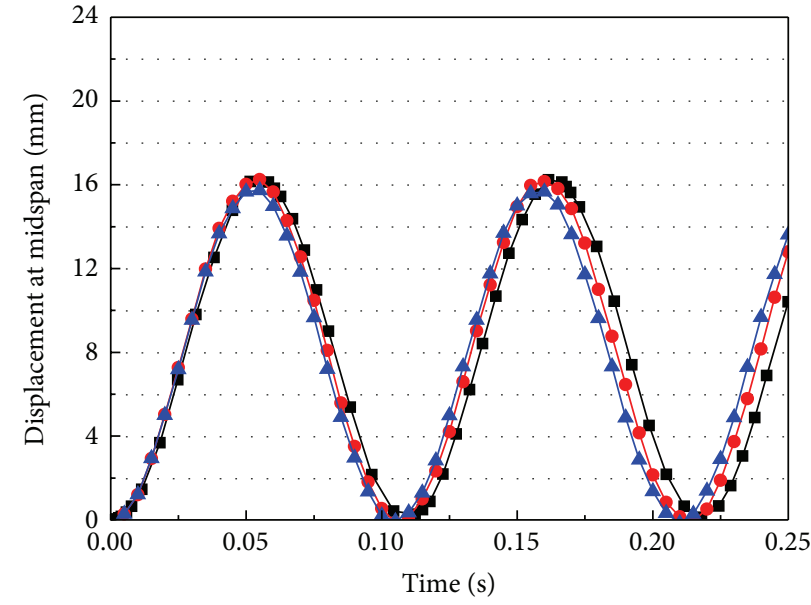

(b) $r=0.5$

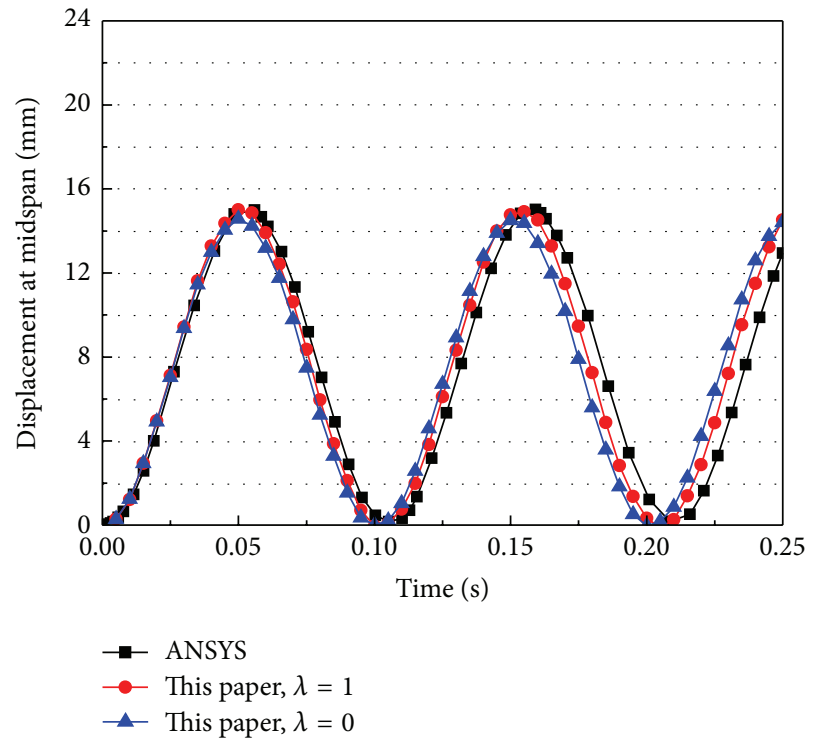

(d) $r=1.5$

FIGURE 3: Displacement time history at midspan of composite beams $(\lambda=1$ represents inclusion of shear lag and $\lambda=0$ is for exclusion of shear lag).

The spring parameter of the COMBIN14 elements can be calculated as [25]

$$
K_{1}=0.66 n_{s} V_{u}
$$

The degree of shear connections is calculated as [5]

$$
r=\frac{n_{s} V_{u} L}{A_{s} f_{s} l}
$$

where $l$ is the spacing of shear connectors; $r$ is the degree of shear connections; $f_{s}$ is the tensile strength of steel beams; $n_{s}$ is the number of connectors across the beam section; $V_{u}$ is the ultimate shear strength of a single shear connector.

From Figures 3 and 4, it can be seen that the results from the proposed method agree well with those from ANSYS for different degrees of shear connections. This verifies the accuracy of the proposed method and some meaningful conclusions for engineering design can be drawn as follows.
(1) For various degrees of shear connections, the vibration period of composite beams with and without shear lag effects is almost the same which indicates that the shear lag and shear connection degree have little impact on the vibration period.

(2) The larger the degree of shear connections, the smaller the amplitude of deflection.

(3) The influence of the shear lag on the amplitude of deflection is not significant, indicating that it has little effect on the deflection of beams.

(4) The longitudinal strain in the concrete slab and steel beam bottom plate shows obvious shear lag effects.

(5) The longitudinal strain in the concrete slab reduces obviously with an increment in the degree of shear 


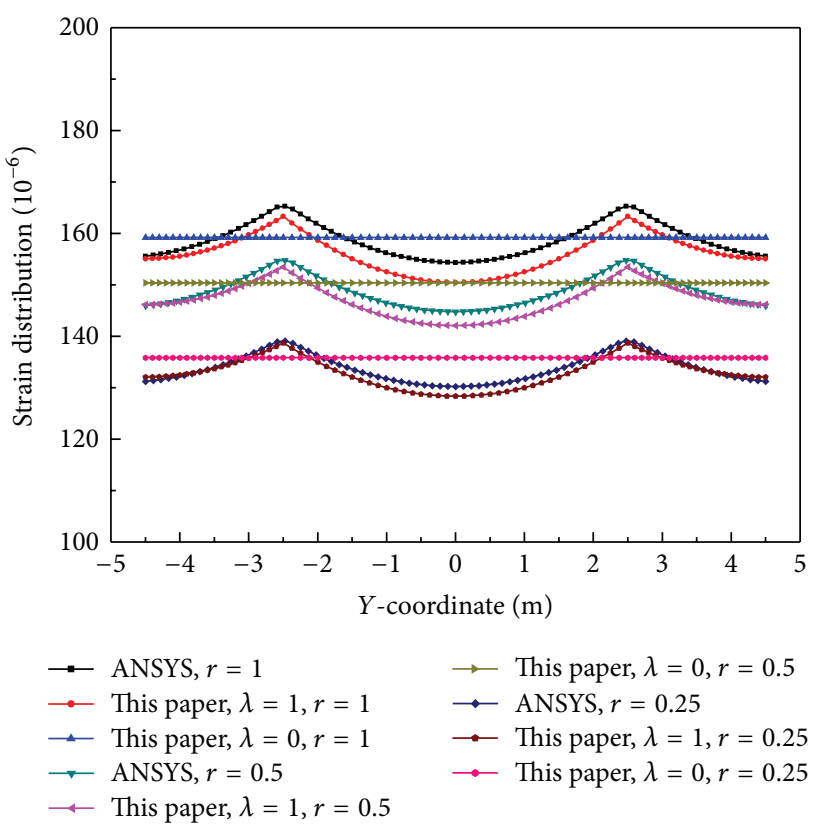

(a) Concrete plate

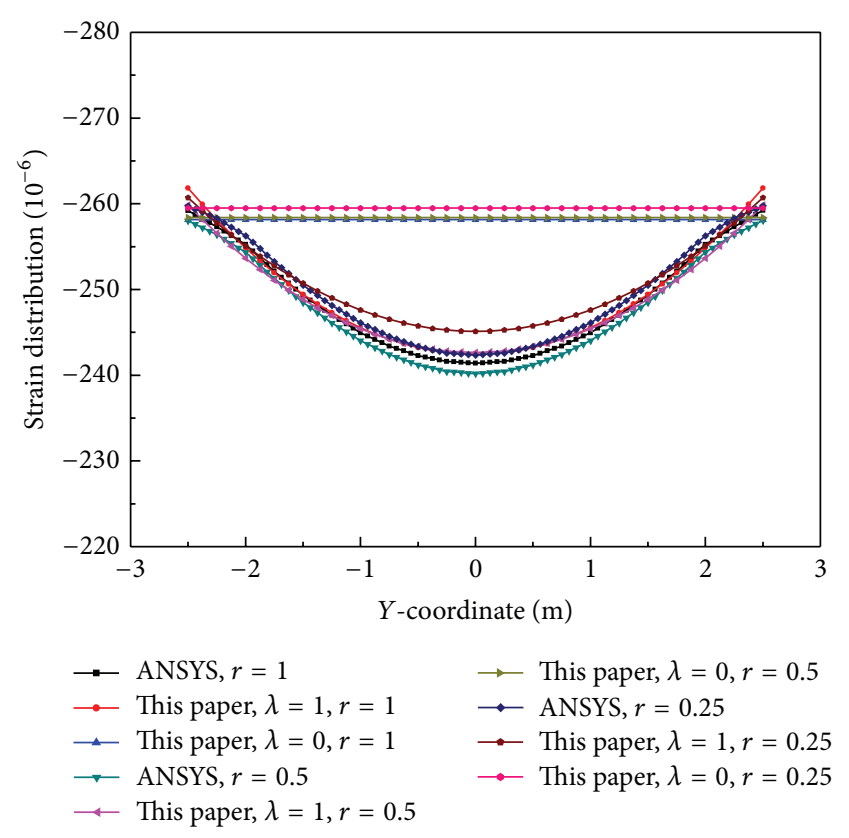

(b) Steel beam bottom plate

FIGURE 4: Strain distribution in the flanges of midspan section $(\lambda=1$ represents inclusion of shear lag and $\lambda=0$ is for exclusion of shear lag).

connections, which indicates that the shear connection degree has a great effect on the longitudinal strain of concrete slab. Nevertheless, the longitudinal strain in the steel beam bottom plate changes little with an increment in the degree of shear connection.

\section{Conclusions}

(1) Numerical analyses are carried out to verify the accuracy of the proposed theory. The comprehensive considerations of shear lag, shear deformation, and interface slip yield an accurate prediction of dynamic responses of composite box beams.

(2) The degree of shear connections has little impact on the vibration period of composite beams but has significant impact on the amplitude of deflection of composite beams. Nevertheless, the shear lag effect has limited contribution to the deflection or the vibration period of composite beams.

(3) The longitudinal strain in the concrete slabs and bottom plate of steel beams shows an obvious shear lag effect.

(4) The longitudinal strain in the concrete slabs reduces greatly with increasing shear connection degree. Nevertheless, the longitudinal strain in the steel beam bottom plate changes little with an increment in the degree of shear connection.

\section{Conflict of Interests}

The authors declare that there is no conflict of interests regarding the publication of this paper.

\section{Acknowledgments}

The research described in this paper was financially supported by the National Natural Science Function of China (51408449, 51378502) and the Fundamental Research Funds for the Central Universities of China (2014-IV-049).

\section{References}

[1] J. Nie and C. S. Cai, "Steel-concrete composite beams considering shear slip effects," Journal of Structural Engineering, vol. 129, no. 4, pp. 495-506, 2003.

[2] F.-F. Sun and O. S. Bursi, "Displacement-based and two-field mixed variational formulations for composite beams with shear lag," Journal of Engineering Mechanics, vol. 131, no. 2, pp. 199210, 2005.

[3] G. Ranzi and A. Zona, "A steel-concrete composite beam model with partial interaction including the shear deformability of the steel component," Engineering Structures, vol. 29, no. 11, pp. 3026-3041, 2007.

[4] Z. Wangbao, J. Lizhong, K. Juntao, and B. Minxi, "Distortional buckling analysis of steel-concrete composite girders in negative moment area," Mathematical Problems in Engineering, vol. 2014, Article ID 635617, 10 pages, 2014.

[5] W.-B. Zhou, L.-Z. Jiang, Z.-J. Liu, and X.-J. Liu, "Closedform solution for shear lag effects of steel-concrete composite box beams considering shear deformation and slip," Journal of Central South University, vol. 19, no. 10, pp. 2976-2982, 2012.

[6] F. Gara, G. Ranzi, and G. Leoni, "Simplified method of analysis accounting for shear-lag effects in composite bridge decks," Journal of Constructional Steel Research, vol. 67, no. 10, pp. 16841697, 2011.

[7] F. Gara, G. Leoni, and L. Dezi, "A beam finite element including shear lag effect for the time-dependent analysis of steel-concrete 
composite decks," Engineering Structures, vol. 31, no. 8, pp. 18881902, 2009.

[8] A. Morassi and L. Rocchetto, "A damage analysis of steelconcrete composite beams via dynamic methods: part I. Experimental results," Journal of Vibration and Control, vol. 9, no. 5, pp. 507-527, 2003.

[9] M. Dilena and A. Morassi, "A damage analysis of steel-concrete composite beams via dynamic methods: part II. Analytical models and damage detection," Journal of Vibration and Control, vol. 9, no. 5, pp. 529-565, 2003.

[10] M. Dilena and A. Morassi, "Vibrations of steel-concrete composite beams with partially degraded connection and applications to damage detection," Journal of Sound and Vibration, vol. 320, no. 1-2, pp. 101-124, 2009.

[11] C. Adam, R. Heuer, and A. Jeschko, "Flexural vibrations of elastic composite beams with interlayer slip," Acta Mechanica, vol. 125 , no. $1-4$, pp. 17-30, 1997.

[12] G. Biscontin, A. Morassi, and P. Wendel, "Vibrations of steelconcrete composite beams," Journal of Vibration and Control, vol. 6, no. 5, pp. 691-714, 2000.

[13] S. Berczyński and T. Wróblewski, "Vibration of steel-concrete composite beams using the Timoshenko beam model," Journal of Vibration and Control, vol. 11, no. 6, pp. 829-848, 2005.

[14] S. Berczyński and T. Wróblewski, "Experimental verification of natural vibration models of steel-concrete composite beams," Journal of Vibration and Control, vol. 16, no. 14, pp. 2057-2081, 2010.

[15] R. Xu and Y. Wu, "Static, dynamic, and buckling analysis of partial interaction composite members using Timoshenko's beam theory," International Journal of Mechanical Sciences, vol. 49, no. 10, pp. 1139-1155, 2007.

[16] X. Shen, W. Chen, Y. Wu, and R. Xu, "Dynamic analysis of partial-interaction composite beams," Composites Science and Technology, vol. 71, no. 10, pp. 1286-1294, 2011.

[17] Z. Shen and H. Zhong, "Static and vibrational analysis of partially composite beams using the weak-form quadrature element method," Mathematical Problems in Engineering, vol. 2012, Article ID 974023, 23 pages, 2012.

[18] A. Chakrabarti, A. H. Sheikh, M. Griffith, and D. J. Oehlers, "Dynamic response of composite beams with partial shear interaction using a higher-order beam theory," Journal of Structural Engineering, vol. 139, no. 1, pp. 47-56, 2013.

[19] J. G. S. da Silva, S. A. L. de Andrade, and E. D. C. Lopes, "Parametric modelling of the dynamic behaviour of a steelconcrete composite floor," Engineering Structures, vol. 75, pp. 327-339, 2014.

[20] S. Lenci and J. Warminski, "Free and forced nonlinear oscillations of a two-layer composite beam with interface slip," Nonlinear Dynamics, vol. 70, no. 3, pp. 2071-2087, 2012.

[21] Q.-H. Nguyen, M. Hjiaj, and P. Le Grognec, "Analytical approach for free vibration analysis of two-layer Timoshenko beams with interlayer slip," Journal of Sound and Vibration, vol. 331, no. 12, pp. 2949-2961, 2012.

[22] W.-A. Wang, Q. Li, C.-H. Zhao, and W.-L. Zhuang, "Dynamic properties of long-span steel-concrete composite bridges with external tendons," Journal of Highway and Transportation Research and Development (English Edition), vol. 7, no. 4, pp. 3038, 2013.

[23] W.-B. Zhou, L.-Z. Jiang, and Z.-W. Yu, "Analysis of free vibration characteristic of steel-concrete composite box-girder considering shear lag and slip," Journal of Central South University, vol. 20, no. 9, pp. 2570-2577, 2013.
[24] W.-B. Zhou, L.-Z. Jiang, Z.-W. Yu, and Z. Huang, "Free vibration characteristics of steel-concrete composite continuous box girder considering shear lag and slip," China Journal of Highway and Transport, vol. 26, no. 5, pp. 88-94, 2013.

[25] J. Nie, J. Fan, and C. S. Cai, "Stiffness and deflection of steelconcrete composite beams under negative bending," Journal of Structural Engineering, vol. 130, no. 11, pp. 1842-1851, 2004. 


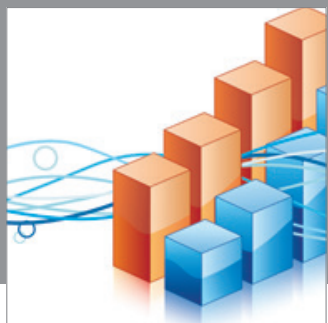

Advances in

Operations Research

mansans

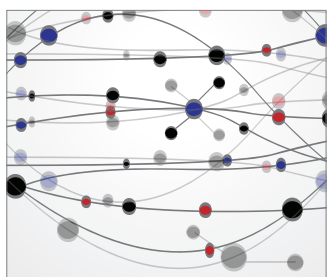

The Scientific World Journal
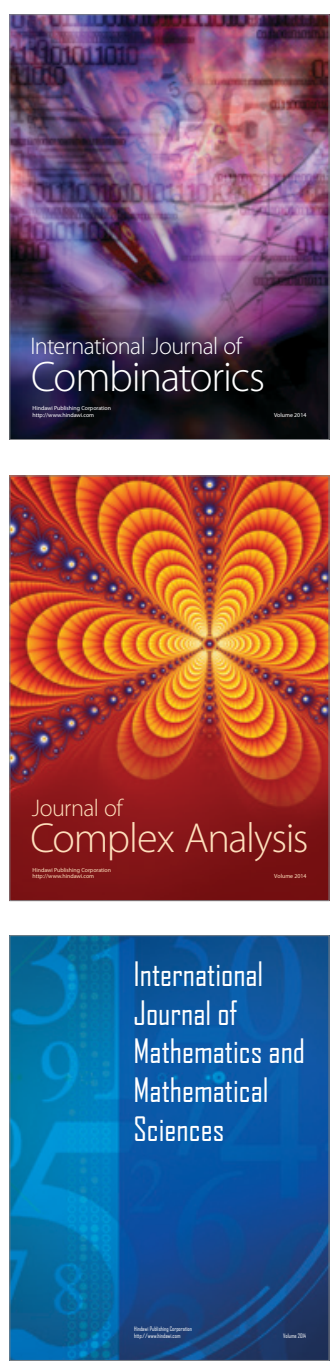
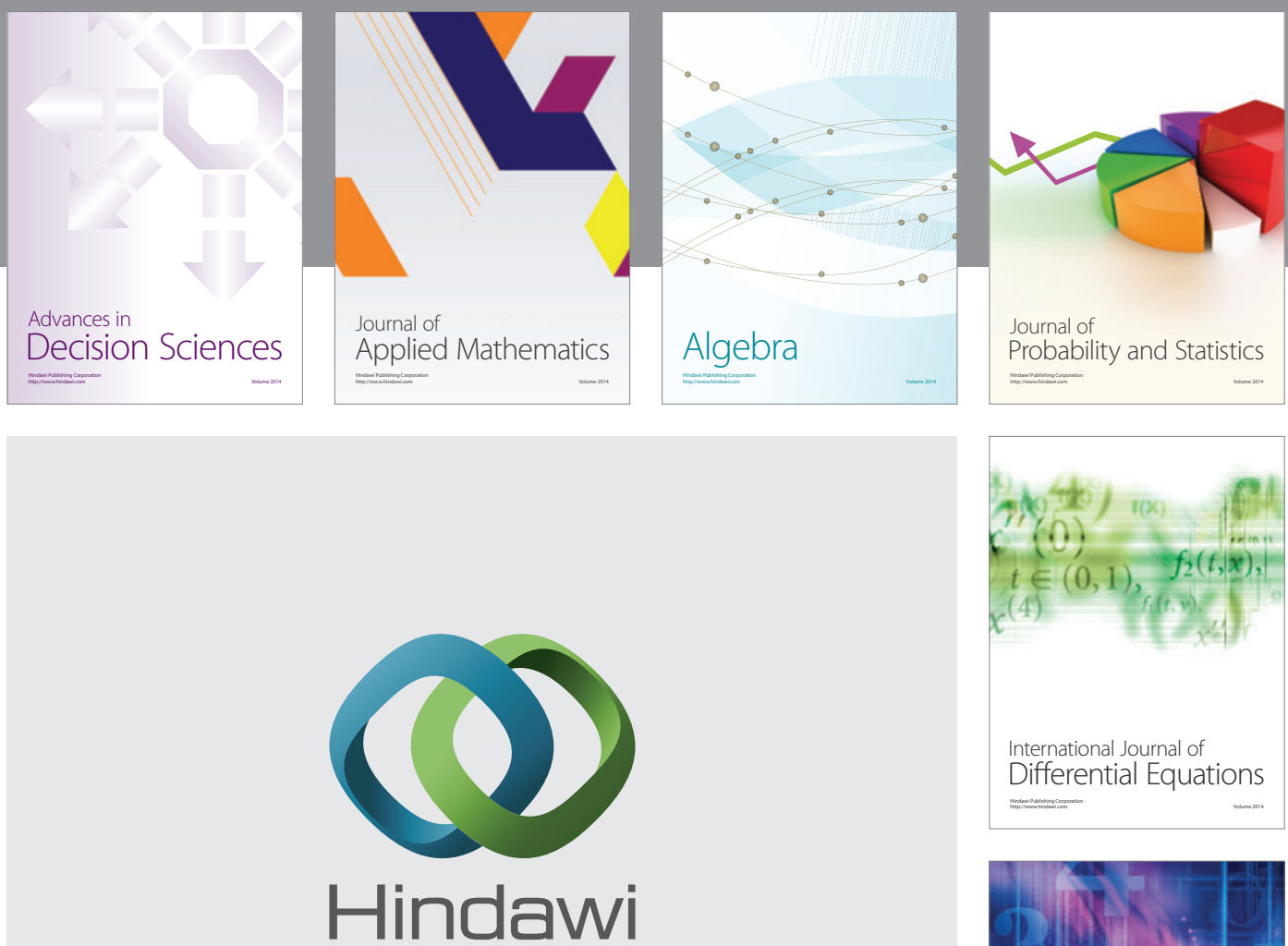

Submit your manuscripts at http://www.hindawi.com
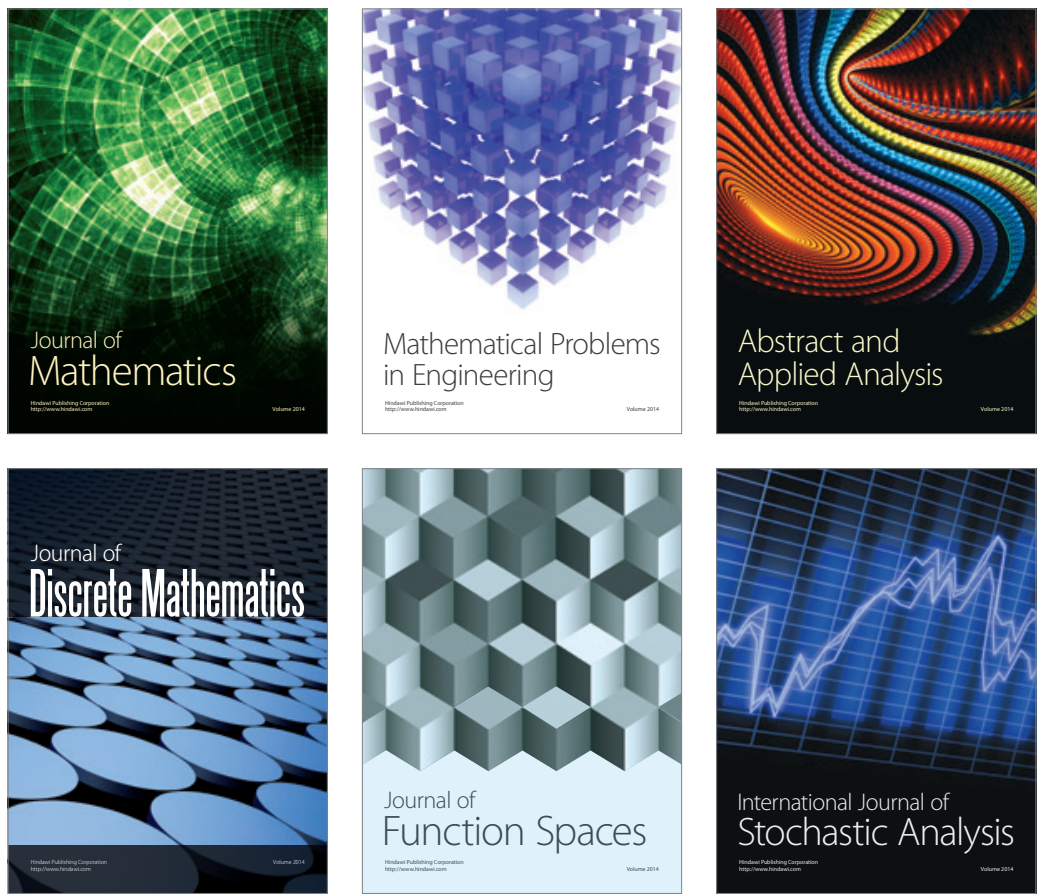

Journal of

Function Spaces

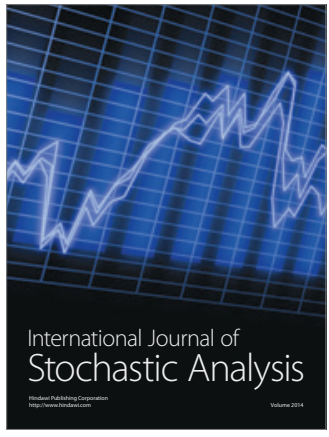

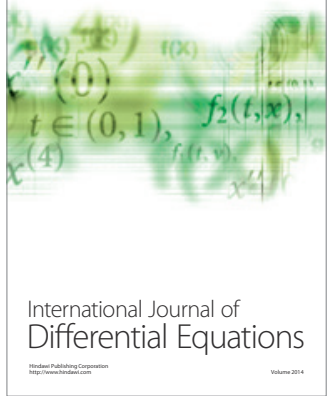
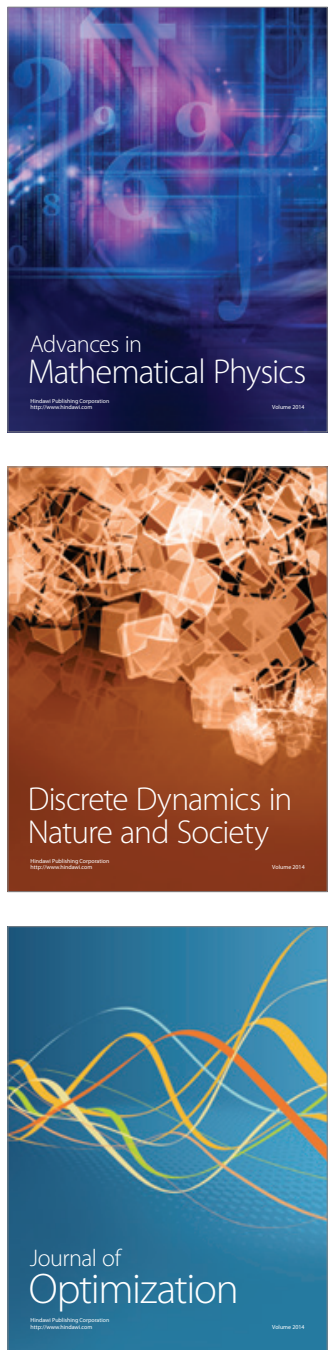